\title{
Implantação da NBR 9050/2015 na adequação de apartamentos acessíveis em um hotel na cidade de São Paulo
}

Vanderlei Fabiano Gonçalves do Monte

Mestre em Cidades Inteligentes e Sustentáveis pelo PPGCIS - Uninove. Graduou-se em Arquitetura e Urbanismo pela Universidade de São Marcos; Professor no curso de arquitetura e urbanismo da UNINOVE, São Paulo, Brasil

arqfabianomonte@gmail.com

Cristiano Capellani Quaresma

Doutor, Mestre, Bacharel e Licenciado em Geografia pela UNICAMP; Professor e pesquisador no Programa de Pós-Graduação em Cidades Inteligentes e Sustentáveis da UNINOVE, São Paulo, Brasil

quaresma.cristiano@gmail.com

Claudia Terezinha Kniess

Doutora em Ciências e Engenharia de Materiais pela Universidade Federal de Santa Catarina; Diretora e Professora no Programa de Pós-Graduação em Cidades Inteligentes - UNINOVE, São Paulo, Brasil

kniesscl@gmail.com

Mauro Silva Ruiz

Doutor em Geografia pela Southern Illinois University at Carbondale; Diretor e professor no Programa de Pós-graduação em Gestão Ambiental e SustentabilidadeUNINOVE, São Paulo, Brasil

maurosilvaruiz@gmail.com

Editor Científico: José Edson Lara
Organização Comitê Científico
Double Blind Review pelo SEER/OJS
Recebido em 16.12.2017
Aprovado em 08.03.2018

\footnotetext{
(c) (1) (8)

Este trabalho foi licenciado com uma Licença Creative Commons - Atribuição - Não Comercial 3.0 Brasil

Resumo
}

Este relato objetivou identificar irregularidades e propor adequações de apartamentos de um hotel no município de São Paulo, com base na Norma de Acessibilidade a Edificações, Mobiliário, Espaços e Equipamentos Urbanos - NBR 
9050/2015. Para identificação das irregularidades, elaborou-se, com base em levantamento fotográfico e modelagem projetual, um laudo demonstrativo das não conformidades em relação à referida norma, o qual foi apresentado à administração da rede hoteleira. Na sequência, elaborou-se projeto preliminar para obtenção de Certificado de Acessibilidade, emitido pela prefeitura do município de São Paulo, e projeto executivo para adequação física do edifício. A elaboração do projeto executivo, em conjunto com laudo técnico, resultou na aprovação do projeto de acessibilidade pelo órgão público mencionado. Além disso, a execução da obra atendeu às exigências de projeto, proporcionando melhorias na acessibilidade e mobilidade de deficientes físicos e de pessoas com mobilidade reduzida.

Palavras-chave: Desenho universal; Acessibilidade hoteleira; ergonomia.

\title{
Implementation of NBR 9050/2015 on the adequacy of accessible apartments in a hotel in the city of São Paulo
}

\begin{abstract}
This report aimed to identify irregularities and propose adjustments to apartment of a hotel in São Paulo, based on the Standard - Accessibility for Buildings, furniture, Spaces and Urban Equipment - NBR 9050/2015. For identification of irregularities was elaborated, based on photographic survey and architectural design modeling, a demonstrative report of nonconformities in relation to that standard, which was presented to the management of the hotel chain. Following, was elaborated preliminary project to obtain the Certificate of Accessibility provided by the City of São Paulo, and executive project for physical adequacy of the building. The preparation of the executive project, together with a technical report, resulted in the adoption of accessibility project mentioned by the public agency. Furthermore, the execution of the project has met the design requirements, providing improvements in accessibility and mobility of people with disabilities or reduced mobility.
\end{abstract}

Key-words: Universal design; hotel accessibility; ergonomics.

\section{Implantación de la NBR 9050/2015 en la adecuación de apartamentos accesibles en un hotel en la ciudad de São Paulo}

\section{Resumen}

Este relato objetivó identificar irregularidades y proponer adecuaciones de apartamentos de un hotel en el municipio de São Paulo, con base en la Norma de Accesibilidad a Edificaciones, Mobiliario, Espacios y Equipamientos Urbanos - NBR 9050/2015. Para identificación de las irregularidades se elaboró, con base en levantamiento fotográfico y modelado proyectual, un laudo demostrativo de las no conformidades en relación a la referida norma, el cual fue presentado a la administración de la red hotelera. En consecuencia, se elaboró un proyecto preliminar para la obtención del Certificado de Accesibilidad, emitido por la 
municipalidad del municipio de São Paulo, y proyecto ejecutivo para adecuación física del edificio. La elaboración del proyecto ejecutivo, en conjunto con laudo técnico, resultó en la aprobación del proyecto de accesibilidad por el órgano público mencionado. Además, la ejecución de la obra atendió a las exigencias de diseño, proporcionando mejoras en la accesibilidad y movilidad de discapacitados y de personas con movilidad reducida.

Palabras clave: Dibujo universal; Accesibilidad hotelera; ergonomía.

\section{Introdução}

No Brasil, segundo dados do IBGE (2010), existiam cerca de 45,6 milhões de pessoas com algum tipo de deficiência. Esse valor representava quase $24 \%$ da população total do país.

Pessoas com deficiência, entendidas como aquelas que apresentam impedimentos de natureza física, mental, intelectual ou sensorial de longo prazo, sofrem com a falta de acessibilidade, o que contribui para a privação de sua liberdade.

Diante da importância do tema, nos últimos anos, têm se intensificado as preocupações para com a questão da acessibilidade dos deficientes físicos no Brasil, fato que pode ser observado a partir das normas e leis instituídas, especialmente, desde o início da década de 1990.

Tais avanços também podem ser observados no campo arquitetônico desde a década de 1950, com o surgimento de projetos visando à inclusão de pessoas com deficiência. Na década de 1980, surge o conceito de Desenho Universal (DU), visando estimular uma arquitetura que atendesse a todas as pessoas, deficientes e não deficientes.

Diante dessa mesma preocupação, criou-se a Norma Brasileira NBR 9050 em 1985, a qual passou por revisões até a mais recente, ocorrida no ano de 2015. Tal norma visa orientar a adequação de edifícios e de mobiliário a pessoas com deficiências.

Com vias a garantir a acessibilidade às pessoas com deficiência, estipulou-se o ano de 2008 como prazo máximo para a adequação de edifícios de uso coletivo às diretrizes estipuladas pela referida norma, por meio do decreto n. 5296/2004.

$O$ atendimento a tal obrigação, entretanto, ainda esbarra nas limitações de conhecimento por parte de profissionais e de proprietários de habitações hoteleiras, os quais se veem diante do desafio de adotar critérios ergonômicos para atender a 
mobilidade de pessoas com deficiência em ambientes internos, sem, no entanto, deterem conhecimentos necessários em relação à norma e à legislação existentes.

Diversos estudos voltados para o entendimento da acessibilidade em hotéis têm apontado a necessidade de ampliação no número de trabalhos que possibilitem a melhor compreensão das condições físicas para a mobilidade de pessoas com deficiência, bem como para a necessidade de desenvolvimento de trabalhos que orientem ações de profissionais do setor, a exemplo de Lattari (2015), Santos (2012), Pereira (2016), entre outros.

Desse modo, o presente relato objetiva demonstrar aos profissionais da área e a empresários do ramo hoteleiro como implantar a NBR 9050/2015, utilizando-se de ferramentas de projeto para a adequação de suítes à acessibilidade de pessoas com deficiência e com mobilidade reduzida, evitando problemas com interpretações equivocadas ou superficiais da norma, e atendendo corretamente a especificações legislativas, sobretudo humanas, bem como diminuindo custos com implantação de equipamentos e obras desnecessárias.

Diante disso, o presente relato foi estruturado em cinco seções. Além da presente introdução, a saber, o referencial teórico, a metodologia adotada, a apresentação e análise dos resultados, as considerações finais e a seção com a citação das referências bibliográficas utilizadas.

\section{Referencial Teórico}

O decreto $n^{\circ}$ 6.949, de 25 de agosto de 2009, instituiu a Convenção Internacional sobre os Direitos das Pessoas com Deficiência, segundo a qual pessoas com deficiência são aquelas que apresentam impedimentos de natureza física, mental, intelectual ou sensorial de longo prazo.

Segundo Torres e Vieira (2014), tais impedimentos, quando interagem com barreiras de ordem física, dificultam a participação plena e efetiva dessa parcela da população na sociedade em condições de igualdade aos demais cidadãos.

Estima-se que no Brasil, existam 45,6 milhões de pessoas com deficiência, quase $24 \%$ da população total, sendo as deficiências declaradas: visual: $18,6 \%$; auditiva: 5,10\%; motora: 7\%; mental ou intelectual: 1,40\% (IBGE, 2010). 
Apesar desses números, a estrutura da sociedade sempre inabilitou os deficientes físicos existentes, promovendo sua marginalização e contribuindo para a privação de sua liberdade (Maciel, 2000).

Entretanto, de acordo com lida (1997), a preocupação para com a questão da acessibilidade dos deficientes físicos tem crescido cada vez mais nas discussões atuais.

De acordo com Castillo (2012), a acessibilidade depende da conjugação de três itens, a saber: os meios materiais, dados pelas condições de infraestrutura; as regulamentações, refletidas em normas e instrumentos legais; e a existência e disponibilização de serviços adequados.

Com relação à legislação brasileira, é possível verificar, nas últimas três décadas, importantes avanços na ampliação da acessibilidade de deficientes físicos. Um exemplo é Lei no. 8.213, de 24 de julho de 1991, que obriga empresas com mais de cem funcionários a preencherem de $2 \%$ (dois por cento) a $5 \%$ (cinco por cento) de seus cargos com beneficiários reabilitados ou com pessoas portadoras de deficiência (BRASIL, 2016).

Outra iniciativa importante foi a criação do Decreto nํ. 5.296, de 2 de dezembro de 2004, que regulamentou a Lei no. 10.048, de 8 de novembro de 2000, a qual dá prioridade de atendimento às pessoas, dentre as quais, com deficiência. $O$ mesmo decreto também regulamentou a Lei no. 10.098, de 19 de dezembro de 2000, que estabelece normas gerais e critérios básicos para a promoção da acessibilidade das pessoas com deficiência ou com mobilidade reduzida.

No campo arquitetônico, as preocupações para com a garantia de acessibilidade aos deficientes físicos e às pessoas com mobilidade reduzida também evoluíram desde o início da década de 1950, momento em que se iniciam projetos visando à inclusão de pessoas com deficiência. Na década de 1970, surgiu, nos EUA e no continente Europeu, o termo projeto acessível, bem como o conceito de Barrier Free Design - Projeto Livre de Barreiras, cujo movimento se estruturava na ideia de que a capacidade funcional da totalidade das pessoas seria destacada com a remoção das barreiras físicas (Bernad \& Kowaltowski, 2005).

Na década de 1980, concebido por Ron Mace, surge o conceito de Desenho Universal (DU), estimulando uma arquitetura que atendesse a todas as pessoas, independentemente de suas limitações ou habilidades (Bernad \& Kowaltowski, 2005). 
De maneira geral, o DU é um conceito que reconhece, valoriza e busca englobar a maior parcela possível da população no desenho dos produtos, ambientes e sistemas de informação. Além disso, o DU visa acabar com a necessidade de equipamentos e espaços especiais, os quais estigmatizam as pessoas, além de terem preços mais elevados (CUD, 2000).

Desse modo, nesse contexto, a acessibilidade toma o significado de não apenas permitir que pessoas com deficiências participem de atividades que incluem o uso de produtos, serviços e informação, mas também a inclusão e extensão do uso desses para a população em geral (lida, 1997; Panero \& Zelnik, 2002).

Ainda no campo arquitetônico, destaca-se que a elaboração do projeto e a adequação de um edifício preexistente às concepções de acessibilidade se tornaram uma necessidade iminente. Isso se deve à criação da Norma Brasileira NBR 9050 pelo Comitê Brasileiro de Construção Civil, pertencente à Associação Brasileira de Normas Técnicas (ABNT), cuja primeira versão é de setembro de 1985. Essa norma, na ocasião, foi intitulada como "adequação das edificações e do mobiliário urbano à pessoa deficiente" e seu objetivo foi o de determinar condições exigíveis, bem como padrões e medidas que poderiam permitir melhores condições de acesso aos edifícios públicos e às vias públicas urbanas (ABNT, 1985).

Conforme destacado por Moraes (2007), essa primeira versão da norma não apresentava a definição de acessibilidade, tão pouco a definição de Desenho Universal.

A norma NBR 9050 sofreu a primeira revisão em outubro de 1994, recebendo o novo título de "acessibilidade de pessoas portadoras de deficiências a edificações, espaços, mobiliário e equipamentos urbanos" (ABNT, 1997).

Moraes (2007) destaca as mudanças dessa versão em relação à anterior, sobretudo em relação ao surgimento do termo acessibilidade, à denominação da pessoa como portadora de deficiência e não mais deficiente, e à aplicação da norma não apenas ao ambiente público, mas também ao privado de uso público e de uso multifamiliar. Além disso, o referido autor destaca que o conceito de acessibilidade contido nessa nova versão não apresenta enfoque nas pessoas com deficiência, demonstrando a influência dos princípios do Desenho Universal.

Outra revisão da Norma NBR 9050 ocorreu em 2004, adquirindo o título de "Acessibilidade e edificações, mobiliário, espaços e equipamentos urbanos" (ABNT, 
2004). A remoção do termo "portadores de deficiência", constante na versão anterior, também reflete a incorporação dos preceitos do Desenho Universal, tendo em vista não limitar a atenção a um grupo particular da sociedade (Moraes, 2007).

A versão de 2004 permanece com o objetivo de "estabelecer critérios e parâmetros técnicos de acessibilidade a serem observados em projetos, construções, instalações e adaptações de edificações, mobiliários, espaços e equipamentos urbanos" (ABNT, 2004).

A revisão mais recente dessa norma ocorreu em 2015, e seus objetivos diferem das versões anteriores ao também abordarem o meio rural e não somente o meio urbano. Além disso, essa versão apresenta informações e ilustrações de maior detalhe das medidas, bem como as formas de adaptá-las conforme a característica de cada modelo (Lima, 2016).

Retornando-se à questão legal, torna-se importante mencionar, no âmbito do presente trabalho, que o Decreto ํo. 5296/2004, mencionado em parágrafos anteriores, determinou prazos para adequação de edifícios de uso coletivo do país às normas que estabelecem critérios para a promoção da acessibilidade de pessoas com deficiência, sendo o limite máximo de dezembro de 2008 para o cumprimento de tal determinação.

Diante do quadro normativo existente, destaca-se a necessidade de contratação de profissionais qualificados para atender essa demanda, fato que resulta na maximização dos espaços, otimização de tempo, economia de custos e mitigação de impactos ambientais devido a reformas (Caubr, 2014).

Para adequações à legislação de acessibilidade em hotéis, são necessários comparativos entre o executado e os parâmetros antropométricos estabelecidos pelas normas e leis. A Secretaria da Pessoa com Deficiência (SMPED) disponibiliza - Manual de Instruções Técnicas de Acessibilidade para Apoio ao Projeto Arquitetônico, que é recomendado pela Prefeitura do Município de São Paulo para adequações de edificações existentes (SMPED \& PMSP, 2005).

De acordo Socytec \& Paradores (2007), as habitações hoteleiras precisam seguir critérios ergonômicos para atender à mobilidade das pessoas com deficiência dentro de ambientes internos (Socytec S.L. \& Paradores de Turismo de España SA, 2007).

\section{Metodologia}


O presente relato pode ser caracterizado como uma pesquisa exploratória e descritiva, adotando como ferramenta metodológica o estudo de caso único, conforme apresentado por Yin (2015).

O hotel, objeto deste relato, pertence a uma rede de hotéis com presença em vários estados do Brasil e em diferentes países do mundo, apresentando padrões de conforto e de atendimento internacionais. Além disso, possui estrutura e equipamentos, os quais, aliados a sua localização privilegiada no centro de serviços da cidade de São Paulo, potencializam a realização de eventos e de reuniões de negócios. Tais qualidades atraem turistas e empresários que o buscam por suas facilidades de mobilidade e de acessibilidade.

Localizado na Alameda Santos, próximo à Avenida Paulista, o edifício foi construído na década de 1990, todavia a empresa administradora existe desde 1946, possuindo atualmente nove redes hoteleiras, com mais de 4.700 hotéis em quase cem países no mundo.

Em dezembro de 2004, o governo federal publicou o Decreto №. 5.296/2004, regulamentando as Leis №. 10.048/2000 e №. 10.098/2000. Tal decreto estabeleceu o prazo máximo de dezembro de 2008 para a adequação de edifícios de uso coletivo do país às normas que estabelecem critérios para promoção da acessibilidade de pessoas com deficiência.

Tendo a época de construção do referido hotel ser anterior à publicação do Decreto

no. 5.296/2004, o imóvel não possuía um espaço projetado que atendesse às necessidades da parcela da população com deficiência.

Com vias a melhor atender a seus clientes e às determinações legais, a administração da empresa hoteleira contratou profissionais para o desenvolvimento de projetos e execução de obra de adequação do edifício às diretrizes estabelecidas pela lei. Entretanto, apesar do investimento da ordem de $\mathrm{R} \$ 30.000,00$, a empresa cometeu falhas ao contratar um profissional que não possuía atribuições para o desenvolvimento desse tipo de adequação projetual. Desse modo, seu trabalho resultou em denúncia junto à Prefeitura do Município de São Paulo, acarretando a aplicação de multa de $R \$ 3.800,00$ ao hotel e o impedimento da renovação de seu 
alvará de funcionamento, fato que gerou maiores prejuízos financeiros e à imagem do hotel em questão.

Buscando a solução para tais problemas e a obtenção do Certificado de Acessibilidade, a administração do hotel contratou uma nova empresa especializada nesse tipo de serviço, cujos procedimentos e resultados encontram-se aqui relatados. Assim, elaboraram-se um laudo demonstrando as não conformidades do prédio às leis vigentes e um estudo que, por meio de simulações gráficas e maquetes eletrônicas, permitiu ilustrar como o projeto atenderia à NBR 9050/2015. Em seguida, foi desenvolvido o projeto executivo para perfeita adaptação e instalação de equipamentos exigidos na intervenção proposta.

Foram realizadas visitas técnicas ao local para fins de reconhecimento, descrição da distribuição das atividades e obtenção de material documental. $\mathrm{Na}$ sequência, realizou-se análise documental das publicações da Prefeitura do Município de São Paulo em relação ao processo do imóvel, com vias a verificar os itens de irregularidade apontados pelos agentes fiscais da prefeitura. Para identificação das irregularidades, elaborou-se, com base em levantamento fotográfico e modelagem projetual, um laudo demonstrativo das não conformidades em relação à norma NBR 9050:2015, o qual foi apresentado à administração da rede hoteleira.

Baseado no Manual de Instruções Técnicas de Acessibilidade para Apoio ao Projeto Arquitetônico da Secretaria da Pessoa com Deficiência (SMPED \& PMSP, 2005), foi elaborado um check list constando os seguintes itens: (1) vãos de porta, (2) box adaptados de sanitários, (3) bacias sanitárias, (4) lavatório, (5) chuveiro, (6) número mínimo de dormitórios em locais de hospedagem, (7) acesso a mesas e (8) altura de cama.

Para a análise da configuração espacial do edifício e da mobilidade e ergonomia para a planta tipo, utilizou-se do método dos parâmetros antropométricos determinados pela NBR 9050:2015(ABNT, 2015), pelo livro Desenho Universal para HIS - Habitação de Interesse Social (CDHU, 2010) e pelo Manual Acessibilidade Universal para Hotéis (Socytec S.L. \& Paradores de Turismo de España SA, 2007).

Para a modelagem gráfica, foram utilizados os softwares AutoCad, 3D Studio Max e Coreldraw. Na sequência, elaboraram-se o projeto preliminar para obtenção de Certificado de Acessibilidade, documento emitido pela prefeitura do município de São Paulo, e o projeto executivo para adequação física do edifício. 


\section{Resultados e discussões}

A análise dos documentos obtidos junto à administração da rede hoteleira permitiu constatar que o hotel em estudo possui uma população fixa de 150 funcionários e uma população flutuante de 500 pessoas entre hóspedes, convidados e prestadores de serviço, tendo uma movimentação total diária estimada de 650 pessoas.

Com relação à distribuição das atividades que se desenvolvem no prédio, verificou-se que a administração se encontra no primeiro subsolo. No pavimento térreo, encontram-se recepção, espaços de convivência e restaurante. Na sobreloja, estão localizadas as salas de reuniões e salões para convenções e para festas. Por fim, do segundo ao vigésimo segundo andar, encontram-se os pavimentos denominados "tipo", nos quais se localizam as suítes para hóspedes.

O prédio recebe pessoas de diversas etnias e países, e, apesar de contar com funcionários treinados para orientação de diversas pessoas, o local não atendia à legislação em relação aos aspectos de acessibilidade a deficientes físicos, resultando em denúncia junto à Prefeitura do Município de São Paulo e à Secretaria da Pessoa com Deficiência Física.

Os agentes fiscais da prefeitura identificaram, em vistoria, irregularidades na edificação, bem como no número de apartamentos adaptados, o qual era insuficiente, estando em desacordo com o Decreto Federal 5296/2004. Desse modo, a administração do hotel foi enquadrada e multada nos termos da lei.

Após o ocorrido, os gestores contrataram profissionais para a realização das obras de adequação dos espaços com vias ao atendimento à legislação. Entretanto, tais profissionais não possuíam qualificações para essa atividade, fato que resultou no desenvolvimento de um projeto e na execução de obra inadequada, gerando a aplicação de nova multa, bem como no indeferimento do projeto e na perda do alvará de funcionamento do estabelecimento.

Essa situação destaca a importância da execução de projetos, principalmente voltados a adequações de acessibilidade, por profissionais qualificados pelo Conselho de Arquitetura e Urbanismo, segundo Resolução no. 51 (CAU-BR, 2013b). 
Como resposta, a administração do hotel contratou nova empresa, que se incumbiu de realizar a adaptação da edificação às exigências legais.

Assim, realizou-se um check list baseado no Manual de Instruções Técnicas de Acessibilidade para Apoio ao Projeto Arquitetônico (SMPED \& PMSP, 2005). Esse check list resultou em um laudo de acessibilidade que especificava, por meio de fotomontagem, as não conformidades com a legislação vigente e com a NBR 9050.

Numa abordagem visual específica do lavatório, percebe-se a identificação de quatro não conformidades, conforme Figura 1.
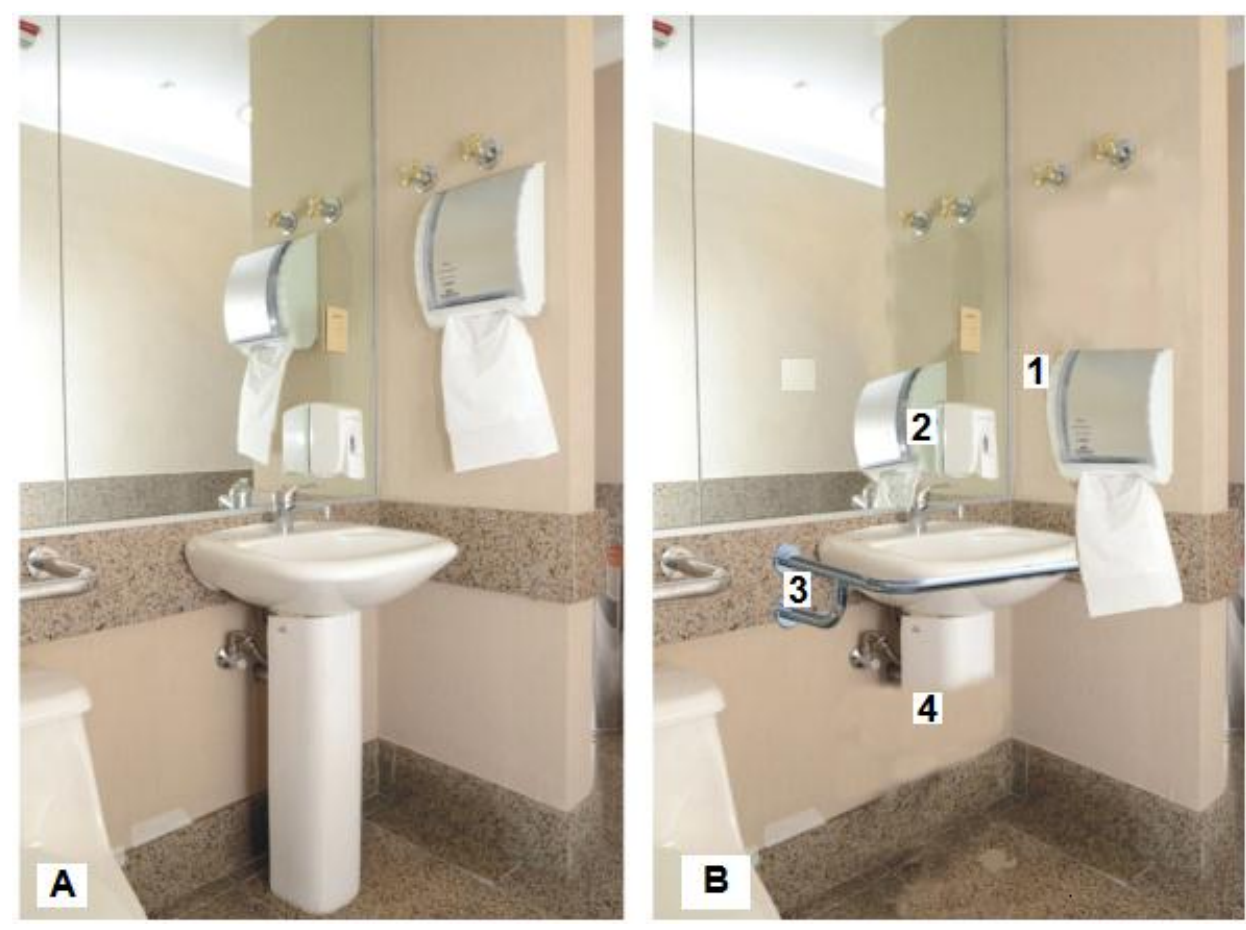

Figura 1

Comparação existente dos pontos conflitantes em adequação a NBR 9050:2015. Fonte: autores.

A fotografia $A$ (à esquerda) da Figura 1 ilustra as condições preexistentes do lavatório, e a fotografia B (à direita) apresenta as sugestões de adaptações necessárias. Entre os problemas encontrados, destacam-se as alturas inadequadas da saboneteira e do toalheiro (1 e 2). Destacam-se, também, a inexistência de barras de apoio para utilização da pia (3) e a presença de coluna na pia, a qual dificulta a aproximação da pessoa em cadeira de rodas para acionamento da torneira (4). 
Com relação aos demais itens do check list pertencentes aos banhos da suíte e constantes no Manual de Instruções Técnicas de Acessibilidade para Apoio ao Projeto Arquitetônico da Secretaria da Pessoa com Deficiência (SMPED \& PMSP, 2005), a saber, vãos de porta, box adaptados de sanitários e chuveiro, verificou-se que sua implantação estava adequada, com exceção para o item bacia sanitária, que possuía barras de apoio em desacordo com a especificação.

Essa metodologia foi realizada em todos os equipamentos das suítes (dormitório e banheiro). Foi constatado que as camas, modelo box, possuíam altura de $50 \mathrm{~cm}$, superior a medida estabelecida pela norma, que é de $46 \mathrm{~cm}$. Os armários não possuíam dispositivo ou cabideiros em altura acessível, e as mesas possuíam altura de tampo de $70 \mathrm{~cm}$, diferente do permitido pela norma NBR 9050, que é de 73 $\mathrm{cm}$. Cabe ressaltar que as dimensões estabelecidas na norma de acessibilidade são medidas absolutas e qualquer alteração, por mínima que seja, impossibilita o uso dos equipamentos por pessoas com deficiência.

$\mathrm{Na}$ abordagem espacial, em posse do projeto as built, que é um termo utilizado para um novo projeto que demonstra a configuração espacial mais recente do edifício (Avila, 2011; Nascimento, 2013), foi feito o levantamento das dimensões existentes in loco para a compatibilização do projeto. Foram também elaboradas as análises de mobilidade e ergonomia para planta tipo das suítes, conforme demonstrado na figura 2, que relaciona as áreas de manobra em relação ao deslocamento interno da suíte e layout. O módulo de referência indicado em cor vermelha tem área de $0,80 \times 1,20 \mathrm{~m}$ e determina a aproximação de equipamentos para ser efetuada sua transferência para uso. A altura mínima dos objetos (cama, cadeira da ducha e bacia sanitária) para a transferência deve ter altura mínima de $0,46 \mathrm{~m}$. As manobras de $360^{\circ}$ (cor laranja) possibilitam o giro completo e acesso para qualquer parte necessária. A manobra de $180^{\circ}$ (cor azul) facilita 0 acesso frontal, e a manobra de $90^{\circ}$ (cor verde), os acessos laterais.

Foi utilizado o método dos parâmetros antropométricos determinados pela NBR 9050:2015(ABNT, 2015), pelo livro Desenho Universal para HIS - Habitação de Interesse Social (CDHU, 2010) e Manual Acessibilidade Universal para Hotéis (Socytec S.L. \& Paradores de Turismo de España SA, 2007). Essa metodologia possibilitou a identificação das manobras possíveis para uma pessoa com cadeira de rodas utilizar todos os equipamentos disponíveis nessa unidade. Demonstrou, 
também, que a Opção 1 aumentaria a área dos banheiros, elevando os custos com materiais e mão de obra, não sendo necessária essa obra, caso optassem pela Opção 2, utilizando o banheiro com suas dimensões originais, acrescentando-se apenas equipamentos como barras de apoio e cadeira para banho.

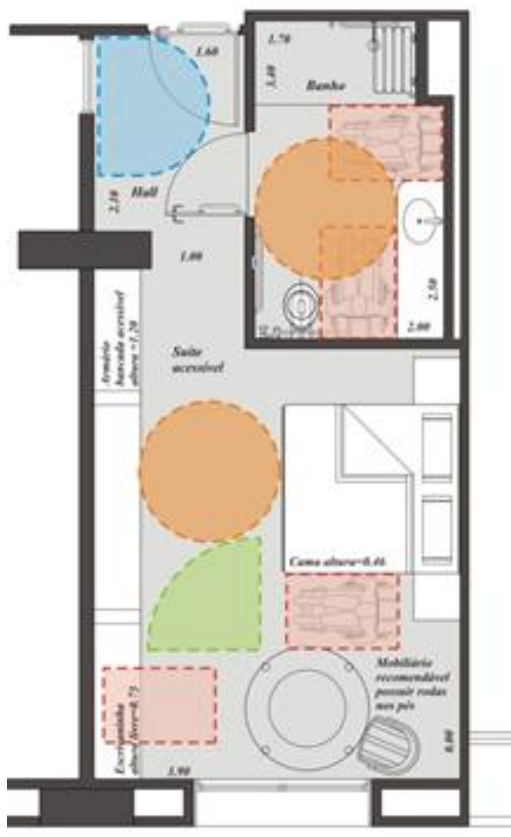

PLANTA APTO. ACESSÍVEL OPCÃO 1

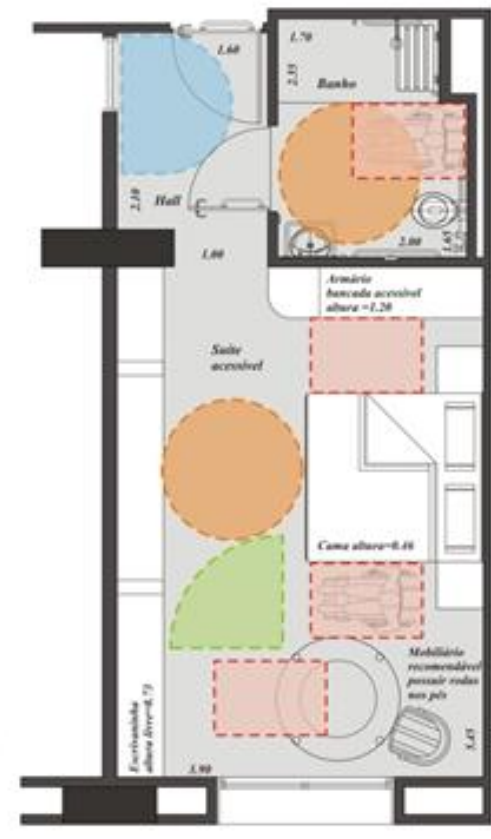

PLANTA APTO. ACESSíVEL OPCÃO 2

Figura 2

Análise de Mobilidade interna da planta tipo da suíte.

Fonte: autores

As metodologias adotadas facilitaram a visualização global do espaço em relação ao layout proposto e estrutura existente, adequando o espaço a normas e resoluções de acessibilidade. As utilizações de softwares de computação gráfica contemplaram o ambiente em três dimensões e apontaram, nas modelagens, as disparidades do layout existente em relação à circulação interna do espaço. A sugestão de novo layout e a reconfiguração das modelagens espaciais demonstraram que as suítes alcançaram um desenho universal, podendo ser utilizadas por qualquer pessoa, e atenderam à norma na especificação que determina que $10 \%$ das suítes devem ser acessíveis, com a possibilidade de amplificação para mais $10 \%$. Com a proposta, todas as suítes do hotel poderão ser adaptadas aos critérios do desenho universal. 
Após análises e implementos das metodologias, elaboraram-se projetos executivos que compreendiam o projeto de arquitetura, projeto de instalações prediais, estrutura e detalhamento de implantação de equipamentos.

Nesse contexto, o projeto foi aprovado pela Prefeitura Municipal de São Paulo, sendo o hotel certificado como acessível e, dessa forma, obtendo o alvará de funcionamento. Atualmente, as reformas de adequação estão sendo implementadas, não havendo adicional de custos significativos ao estabelecimento. O projeto de adequação contratado proporcionou uma melhor análise de gestão administrativa em relação às reformas gerais do local.

\section{Conclusões}

O presente relato contribui para com iniciativas que visem à adequação de ambientes, especialmente ligados à rede hoteleira, às exigências legais, no que concerne à criação de ambientes acessíveis.

Destaca-se que a concepção de um ambiente acessível, segundo os princípios do Desenho Universal, amplia o atendimento às necessidades não somente dos deficientes físicos, mas à totalidade das pessoas. Desse modo, a acessibilidade deve receber uma abordagem de projeto com vias à proposição de soluções centradas na diversidade humana, procurando, assim, contribuir para uma sociedade mais justa e mais inclusiva, na qual todas as pessoas tenham direitos iguais às oportunidades.

As adequações das suítes não se limitaram ao mínimo exigido pela legislação. Além disso, a metodologia adotada e as modelagens realizadas servem como incentivo para que outras empresas do ramo hoteleiro tomem ciência de que é possível a adequação de todas as unidades de apartamentos ao Desenho Universal, sem que haja necessidade de grandes gastos de ordem econômica ou de profundas transformações estruturais.

É importante destacar, enquanto desafio ainda existente à adaptação de suítes de hotéis, os impasses de ordem cultural, refletidos no fato de não serem as adaptações bem recebidas por parte da população, tendo em vista que, segundo os administradores do hotel estudado, existem relatos de repúdio ao uso de suítes que possuem equipamentos que facilitam o uso por pessoas com deficiência. 
Destaca-se, por fim, a necessidade de se pensar na realização de futuras análises antropométricas das etnias brasileiras para aproximar as adequações à realidade do país, tendo em vista que as normas adotadas se baseiam em modelos internacionais.

\section{Referências}

Associação Brasileira de Normas Técnicas - ABNT(2015). NBR 9050: Acessibilidade a edificações, mobiliário, espaços e equipamentos urbanos, ABNT NBR 9050:2015 148 .

Associação Brasileira de Normas Técnicas - ABNT(2004). NBR 9050: Acessibilidade a edificações, mobiliário, espaços e equipamentos urbanos. 2004. Rio de Janeiro: ABNT.

Associação Brasileira de Normas Técnicas - ABNT(1997). NBR 9050: Acessibilidade de pessoas portadoras de deficiências a edificações, espaço, mobiliário e equipamento urbanos. Rio de Janeiro: ABNT.

Associação Brasileira de Normas Técnicas - ABNT(1985). NBR 9050: adequação das edificações e do mobiliário urbano à pessoa deficiente.

Avila, V. M. (2011). Compatibilização de Projetos na Construção Civil: estudo de caso em um edifício residencial multifamiliar, 86.

Bernard, N., Kowaltowski, D. C. C. K. (2005). Reflexões sobre a aplicação dos conceitos do desenho universal no processo de projeto de arquitetura. Anais do ENCAC, Maceió, alagoas, AL, Brasil.

Cambiaghi, S., \& Carletto, A. C. (2005). Desenho Universal: Um conceito para todos. São Paulo: Company SA.

Castillo, R. (2012). Redes geográficas e território brasileiro. Relatório de Atividades apresentado ao Instituto de Geociências da Universidade Estadual de Campinas, referente a Licença Especial, no período de 01 de setembro de 2011 a 29 de fevereiro de 2012.

CAU-BR. (2013). Resolução n. 51, Pub. L. nº. 51. Recuperado de http://www.caubr.gov.br/wp-content/uploads/2012/07/RES512013ATRIBPRIVATIVAS20-RPO-1.pdf

CAU-BR. (2014). 6 dicas para contratar um arquiteto. Recuperado de http://arquiteturaurbanismotodos.org.br/6-dicas-para-contratar-um-arquiteto/

Center For Universal Design - CUD (2000). Universal Design Exemplars. Escola de Design, Universidade do Estado da Carolina do Norte. CD-ROM. 
Decreto n. 6.949 (2009a, 25 de agosto). Disponível em: http://www.planalto.gov.br/ccivil_03/_ato2007-2010/2009/decreto/d6949.htm

Decreto n. 5.296 (2004, 2 de dezembro). Diário Oficial da União. Disponível em http://www.planalto.gov.br/ccivil_03/_ato2004-2006/2004/decreto/d5296.htm

Duarte, D.C., \& Pereira, J. C. R. (2017). Acessibilidade para pessoas com deficiência visual nos hotéis dos Setores Hoteleiros Sul e Norte de Brasília (DF). Disponível em: file://C:/Users/Let\%C3\%ADcia/Desktop/G\%20T\%20mar\%C3\%A7o/2665786075-1-PB.pdf

Governo do Estado de São Paulo (2010). Desenho Universal: Habitação de Interesse Social. São Paulo: Imprensa Oficial do Estado de São Paulo. Recuperado de http://www.mpsp.mp.br/portal/page/portal/Cartilhas/manualdesenho-universal.pdf

Instituto Brasileiro de Geografia e Estatística - IBGE (2010). Censo Demográfico 2010: Pessoas com deficiência - Amostra. Recuperado de http://www.ibge.gov.br/estadosat/temas.php?tema=censodemog2010 defic

Lei n. 8.213, de 24 de julho de 1991. Disponível em: <http://www.planalto.gov.br/ccivil_03/leis/L8213cons.htm>. Acesso em: 17 mai. 2017.

lida, I. (1997). Ergonomia, Projetos e Produção (4a ed.). São Paulo: Edgard Blucher.

Lattari, A. B. (2015). Acessibilidade em hotéis: a visão dos cadeirantes e da hotelaria da zona sul carioca. Disponível em: https://app.uff.br/riuff/bitstream/1/1157/1/72\%20-\%20Aline\%20Lattari.pdf

Lima, A. B. L. D. (2016). Análise da acessibilidade do Parque Natural Municipal Victório Squierolli (Uberlândia/MG) para visitação de pessoas com deficiências física, auditiva e visual. Disponível em: https://repositorio.ufscar.br/handle/ufscar/8530

Maciel, M. R. C. (2000). Portadores de deficiência: a questão da inclusão social. São Paulo em perspectiva, 14(2), 51-56.

Moraes, M. C. D. (2007). Acessibilidade no Brasil: análise da NBR 9050. 2007 (Dissertação de Mestrado em Arquitetura e Urbanismo pelo Programa de PósGraduação em Arquitetura e Urbanismo, Universidade Federal de Santa Catarina, SC, Brasil). Disponível em: https://repositorio.ufsc.br/handle/123456789/90530

Nascimento, J. M. (2013). A importância da compatibilização de projetos como fator de redução de custos na construção civil. Revista OnLine IPOG, 11. 
Panero, J., \& Zelnik, M. (2002). Dimensionamento Humano para Espaços Interiores: Um livro de consulta e referência para projetos (1.). Barcelona: Gustavo Gili.

Pinhal, C. dos A. (2014). O que as built? Terminologias Arquitetônicas. Recuperado de http://www.colegiodearquitetos.com.br/dicionario/2014/03/asbuilt/

Prefeitura Municipal de São Paulo (2005). Manual de Instruções Técnicas de Acessibilidade para Apoio ao Projeto Arquitetônico: Princípios básicos, diretrizes e check list. São Paulo: Imprensa Oficial do Estado de São Paulo. Disponível em: http://www.prefeitura.sp.gov.br/cidade/secretarias/upload/pessoa_com_deficiencia /manual\%20acessibilidade.pdf

Portal Brasil. (2012, 25 de julho). Lei que regula a contratação de pessoas com deficiência completa 21 anos - Portal Brasil. Recuperado de http://www.brasil.gov.br/economia-e-emprego/2012/07/lei-que-regula-acontratacaode-pessoas-com-deficiencia-completa-21-anos

Santos, L. N. D. (2012). Abordagem da ergonomia para análise da acessibilidade a hóspedes com deficiência visual em hotéis: soluções de inclusão de pessoas cegas e com baixa visão (Dissertação de Mestrado. Universidade Federal do Rio Grande do Norte, RN, Brasil). Disponível em: https://repositorio.ufrn.br/jspui/handle/123456789/15035

Socytec S. L., S. y T., \& Paradores de Turismo de España SA. (2007). Manual de Accesibilidad Universal para Hoteles. Madrid: Real Patronato.

Torres, V. M. F., \& Vieira, S. C. M. (2014). Qualidade de vida em adolescentes com deficiência. Rev. CEFAC, 16(6), 1953-1961. 